\title{
Claves didácticas en un manual de astronomía: De Sphaera Mundi de Sacrobosco
}

\section{Marta Gómez Martínez*}

UNIVERSIDAD DE LA RIOJA

En este artículo se analizan aquellos aspectos estructurales y conceptuales de carácter didáctico presentes en las traducciones al castellano de De Sphaera Mundi de Sacrobosco, el que fuera el manual de astronomía empleado en la universidad europea occidental desde el siglo XIII hasta el XVII. Las opciones que presentan los traductores, ya se refieran a la estructura del libro, a la disposición de los contenidos o la elección del léxico de especialidad, muestran las claves didácticas de este manual, esto es, la intención del autor por transmitir el conocimiento especializado. De Sphaera Mundi recoge los contenidos básicos sobre el universo que venían circulando desde la Antigüedad, por lo que resultaba un manual fundamental como introducción al estudio de la ciencia del cielo y las estrellas.

(Didáctica, historia de la astronomía, historia de la traducción, léxico de especialidad)

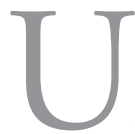

$n$ manual para la enseńanza de una materia que se mantiene vigente a lo largo de los siglos, reeditado en su lengua original y también traducido a otras lenguas, debía contar con algunas claves didácticas que lo hicieran sobresalir y sobrevivir a los cambios sociales, políticos, religiosos y científicos. Este es el caso de De Sphaera Mundi, empleado en la enseńanza universitaria desde

*marta.gomez@unirioja.es

La investigación necesaria para llevar a cabo este trabajo se ha financiado con la ayuda del Ministerio de Ciencia e Innovación de España al proyecto "Lexicografía y ciencia: otras fuentes para el estudio histórico del léxico especializado y análisis de las voces que contienen" (FFI2011-23200). 
el siglo XIII hasta el XVII en su lengua original, el latín, con y sin comentarios, además de ser traducido a otras lenguas como el francés, el alemán, el italiano o el castellano. Por ello en este artículo pretendo mostrar esos aspectos de su estructura y presentación de contenidos que hicieron de él el manual por excelencia para la enseñanza de la astronomía en el Quadrivium y, como veremos, manual de referencia para el conocimiento de la ciencia del cielo y las estrellas presente en bibliotecas privadas.

\section{ConteXto de LA Universidad Medieval}

De Sphaera Mundi fue compuesto por Johannes de Sacrobosco en París en el siglo XIII, época en que las escuelas catedralicias de la ciudad habían ido transformándose en studium generale o universi$\mathrm{dad}$. Aunque no tenemos suficientes datos para conocer la nacionalidad de Sacrobosco, de entre la escasa información de que disponemos sobre su vida, podemos destacar el testimonio de Bartolomeo de Parma (finales del siglo XIII) en su comentario a $D e$ Sphaera Mundi, donde recoge que Sacrobosco redactó el manual cuando se encontraba en la Universidad de París (Thorndike 1949, 2). En realidad no sabemos si llegó a la Universidad de París como estudiante para finalizar sus estudios en la facultad de artes o si llegó como maestro cualificado para enseñar (Pedersen 1985: 195).

El manual objeto de análisis en este artículo se origina y configura en el contexto del nacimiento de las universidades. La universidad, como centro de educación superior, surgió de la necesidad generada por la sociedad del momento y se convirtió en el medio a través del cual la Europa occidental organizó, absorbió y difundió el gran volumen de nuevos conocimientos heredados de la Antigüedad a través, en gran medida, de las traducciones al latín que se habían venido realizando durante el siglo XII (Grant 1986, 20); se había producido, en este momento, una explosión de traducciones del árabe al latín provocando que un amplio repertorio de ciencia y filosofía grecoarábiga entrara a formar parte del corpus de conocimiento científico que necesitaba de un centro de educación que pudiera gestionarlo y difundirlo. En el esquema de la universidad 
medieval, dividida en cuatro facultades -artes, derecho, medicina y teología- no tenía cabida una facultad de ciencias, sino que el estudio de estas materias se realizaba dentro de la facultad de artes organizada bajo el esquema de las artes liberales. La clasificación de las artes en dos áreas principales de conocimiento, el Trivium, que recogía materias de carácter humanístico (gramática, retórica y lógica), y el Quadrivium, las relacionadas con las ciencias (aritmética, geometría, astronomía y música) (Grant 1996, 14; Leff 1994, 351), no era más que una agrupación heterogénea de conocimientos cuya función y nexo de unión era su carácter introductorio. Esta facultad era imprescindible para cualquier estudiante que iniciara sus estudios superiores y suponía el paso previo antes de cursar estudios en cualquiera de las otras tres facultades; por ello se trataba de una escuela para principiantes, para aquellos estudiantes de catorce o quince años recién salidos de las escuelas catedralicias o municipales. De aquí podemos deducir que no sólo los alumnos eran jóvenes sino también inmaduros intelectualmente, pues sus conocimientos se reducían a ciertas nociones de latín, suficientes para poder asistir a clase y participar en debates en esa lengua, y a algunas nociones elementales de aritmética y el sistema numérico romano, pero en ningún caso se les había proporcionado una formación en materia de ciencia. Así, la enseñanza universitaria del Quadrivium debía empezar desde cero con cursos introductorios y libros de texto básicos o elementales, por lo que podemos hacernos una idea del nivel de conocimiento y madurez de los estudiantes que Sacrobosco tenía en sus clases de astronomía y matemáticas, a quienes iban destinados sus libros (Pedersen 1985, 193). Elaboró, por tanto, De Sphaera Mundi, con la intención de presentar a sus alumnos, que apenas tenían nociones de astronomía, un texto básico y, por lo tanto, introductorio a la materia celeste. Quizá sea éste uno de los factores que influyeron en su amplia difusión; sin embargo, el hecho de ser introductorio no implica que no exista una complejidad en la selección de los contenidos y en su disposición didáctica, como veremos a través del estudio y análisis de las traducciones al castellano. ${ }^{1}$

${ }^{1}$ Los ejemplos aquí mostrados están tomados de la edición crítica de cinco traduc- 


\section{EsTRUCTURA DEL MANUAL A TRAVÉS DE LAS TRADUCCIONES}

Como hemos señalado anteriormente, De Sphaera Mundi es un manual básico de astronomía que se convirtió en libro de texto esencial del Quadrivium durante toda la Edad Media, llegando su influencia hasta el siglo Xvir. Su éxito se debió en gran parte a la sencillez con que Sacrobosco expuso las ideas esenciales de su época sobre astronomía y cosmografía: el primer capítulo trata de la estructura general del universo; en el segundo se describen los círculos de la esfera celeste; en el tercero se explican los fenómenos causados por la rotación diaria del cielo visto desde los distintos climas del mundo; y por último, el capítulo cuarto trata los movimientos de los planetas, y en concreto del Sol y de la Luna, así como los eclipses. La información y los temas se presentan de manera ordenada: de lo más cercano a la realidad del lector a lo más lejano, esto es, partiendo de la estructura de la esfera terrestre se pasa a explicar la esfera celeste y los planetas.

Todos los testimonios del manual en castellano analizados (tres manuscritos y cuatro impresos) mantienen esta estructura básica en cuatro capítulos, aunque cada uno muestra unas peculiaridades en su presentación.

El texto de Torres (1487), quien fuera catedrático de Astrología en la Universidad de Salamanca, es un manuscrito que carece de decoración, aunque el autor dejó espacio para, posteriormente, decorar las capitales iniciales. Además, presenta multitud de tachadu-

ciones de De Sphaera Mundi de Sacrobosco realizada por Gómez Martínez (2006): Tratado de la espera copilado por maestro Johan de Sacrobosco de Diego de Torres (1487) [DDT]; Libro o tratado que se dize de la espera trasladado de latín en romance del Maestro de Veas (1493) [MDV]; la versión anónima sin fecha de composición, pero presumiblemente de finales del siglo xv, Tratado de la espera copilado por mastre Johan de Sacrobosco [COL]; Tratado de la esfera que compuso el doctor Joanes de Sacrobusto con muchas adiciones, agora nuevamente traduzido de latín en lengua castellana de Jerónimo de Chaves (1545) [CHA] y La Esfera de Juan de Sacrobosco nueva y fielmente traduzida de latín en romance de Rodrigo Sáenz de Santayana y Espinosa (1568) [sAN]. También hemos consultado otros textos inéditos como Esfera del universo de Ginés Rocamora y Torrano (1599) [GRT] y Exposición de la esfera de Juan de Sacrobosco doctor parisiense, traduzida de latín en lengua vulgar, aumentada y enriquecida, con lo que d'ella dixeron Francisco Juntino, Elias Veneto, Cristóforo Clavio, y otros sus expositores y comentadores de Luis de Miranda (1629) [LDM]. 
ras y enmiendas realizadas al margen por la misma mano. No aparecen figuras ni ilustraciones a pesar de que, como se recoge en el cuerpo textual, debería haber cuatro; sí hay, en dos ocasiones, espacio para ellas, en los folios [188r] y [198v]. La disposición del texto de Diego de Torres se caracteriza por la organización en dos columnas, la falta de ornamentación o el reducido tamaño de la letra de trazo rápido y con multitud de abreviaturas. Sin embargo, a diferencia de otros manuales universitarios, éste no está dividido en secciones que puedan facilitar la lectura, el seguimiento y, por consiguiente, la comprensión del contenido. Esta versión se ha conservado en un códice junto a otras obras de astronomía de marcado carácter matemático.

El manuscrito elaborado por el Maestro de Veas (1493) se trata de un texto decorado con capitales muy ornamentadas en varios colores (rojo oscuro, azul y oro) y con tres dibujos astronómicos a pluma, en el folio [3r], en el [3v] y en el [24r], el primero de ellos con una mano sujetando la esfera ańadida con posterioridad. Además, los títulos de capítulos, el subrayado de los fragmentos en latín y los calderones están en tinta roja. El uso de varios colores implica mayor coste de producción y mayor valoración del libro.

Por su parte, el último manuscrito estudiado, el anónimo conservado en la Biblioteca Colombina (finales del siglo Xv), carece de cualquier tipo de ornamentación, como las capitales decoradas. Además, sólo aparece una ilustración, en el folio [6r], aunque en otros momentos del texto el autor dejó un espacio en blanco para la figura, como por ejemplo en el folio [7v]. Está escrito en una columna y en escritura gótica cursiva procesal de trazo complejo y multitud de abreviaturas, lo que dificulta la lectura. Se ha conservado en un códice junto a otras obras de carácter astronómico.

En cuanto a los impresos, el de Jerónimo de Chaves (1545) presenta las capitales decoradas, normalmente de un tamańo mayor al comienzo de cada capítulo, los títulos están resaltados e incorpora una serie de notas marginales que pueden ser de diferente naturaleza, esto es, son notas de tipo bibliográfico, notas explicativas o notas de llamada de atención que remiten a un comentario. Además, abundan las figuras ilustrativas de las explicaciones, así como tablas 
y un índice al final. En cuanto a la tipografía, muestra un tamaño de letra menor en los escolios o explicaciones del traductor; sin embargo, la adición de texto más notable es la incorporación de una teoría planetaria [85v-92r] -era habitual encontrar en el mismo códice el tratado de Sacrobosco junto al texto anónimo Theorica Planetarumquizá debido a que el capítulo 4 de De Sphaera Mundi carecía de precisión en la explicación de los movimientos planetarios y resultaba un tanto escaso para alguien como él, Titular de la Cátedra de Arte de Navegación y Cosmografía de la Casa de Contratación de Sevilla, que colaboraba en la preparación de pilotos y cosmógrafos.

El impreso de Sáenz de Santayana (1568) también presenta capitales decoradas y títulos resaltados del resto del texto. Las explicaciones del autor están escritas en letra cursiva. Incorpora, como otros impresos, multitud de ilustraciones y tablas y un índice de contenidos al final.

Ginés Rocamora y Torrano (1599) [GRT], regidor de Murcia y procurador en Cortes, tradujo el texto de Sacrobosco incluyéndolo en su obra Esfera del universo, un resumen de las explicaciones que dio en Madrid en la posada en la que residió durante su estancia en la Corte, de ahí que el texto esté impreso en Madrid (López Piñero et alii 1983: s.v. Ginés Rocamora y Torrano), por ello no presenta adición de comentarios, aunque sí tablas y dibujos y está organizado en capítulos y secciones introducidos por títulos que facilitan la lectura.

El impreso de Luis de Miranda (1629), al igual que los anteriores, está dividido en capítulos introducidos por títulos con diferente tamańo de letra y resalte tipográfico; además, presenta un resumen al inicio de cada capítulo: "CAPÍTULO III. En el cual se dize qué cosa sea día y qué cosa sea hora; y se trata de la diversidad de los días y de las noches, ansí naturales como artificiales" [LDM 208]. Destaca también por incorporar comentarios al texto original, notas marginales, tablas, ilustraciones y un índice de contenidos organizado onomasiológicamente.

Como hemos señalado, destacan los impresos de Chaves, Sáenz de Santayana y Luis de Miranda por incorporar adiciones fuera del cuerpo textual o extratextuales, como ocurre en la actualidad con el libro del profesor, que incluye actividades y reflexiones adicionales 
como complemento al contenido básico del libro del alumno. El traductor, en estos apartados, se convierte en autor de un nuevo material que completa y complementa la información presentada en el cuerpo textual del original, que, como hemos advertido en el caso de Chaves, también puede ser susceptible de incorporar nueva información. El traductor, además, deja constancia de que se trata de un trabajo distinto pues estos comentarios se desmarcan del resto tipográficamente gracias a la reducción del tamaño de letra en Chaves, al empleo de la cursiva en el caso de Sáenz de Santayana o de la letra redonda en el de Luis de Miranda, y de títulos introductorios, como "Al Cap....Exposición" [SAN] y "Escolio..." [CHA], o de cierre, "Esta conclusión es de Sacrobosco" [LDM 4].

Los cuatro impresos se apartan del resto de testimonios de $D e$ Sphaera Mundi por incluir un índice al final: mientras Chaves, Sáenz de Santayana y Rocamora y Torrano recogen una tabla de contenidos organizada por números de páginas, Miranda, ofrece una "Tabla de las cosas contenidas en este tratado de la exposición de la esfera de Juan de Sacrobosco" en la que agrupa, onomasiológicamente, los contenidos del manual y los presenta ordenados alfabéticamente:

Aire.

El aire es el tercero en orden de los cuatro elementos, que cerca y rodea al agua y toda la Tierra que está descubierta. Página 26.

Año.

Año solar, qué cosa sea y cuántos días tenga. Página 276.

De la diferencia que ay del año romano al solar. Página 277.

Por la estructura que presenta el manual suponemos que en las clases de Sacrobosco no existía el típico esquema pregunta-respuesta (quaestiones-responsiones) ni tampoco una dependencia extrema en los libros de texto porque él utilizaba el suyo propio. Sin embargo, en cuanto De Sphaera se convirtió en libro de texto habitual los comentaristas en seguida lo fragmentaron en secciones y lectiones. Los impresos de Chaves y Miranda presentan también esa división en secciones y, como se ha comentado unas líneas más arriba, ambos 
textos incorporan notas marginales que pueden ser de diversa naturaleza: notas explicativas en que el traductor ańade información que considera pertinente para la comprensión del tema tratado: "en este tiempo es de veinte y III grados y veinte y nueve minutos y treinta, según lo cual algunas vezes experimenté" [CHA 44r]. También hallamos notas de referencia cruzada que llevan al lector a otro lugar del libro para ampliar los datos aportados; estas notas marginales pueden remitir a otro capítulo del libro o también pueden remitir, en el caso del texto Chaves, a los comentarios que introduce el traductor fuera del cuerpo textual por medio del empleo de letras mayúsculas. Y, por último, otras notas contienen información bibliográfica complementaria que indican al lector de dónde se ha tomado la información: "Lucano, Libro ix de la Farsalia" [CHA 70v]; "Arist. lib. 2 de gen. \& corru." [LDM 121].

Cuestiones como las planteadas anteriormente nos advierten que el texto podía ser empleado, no solo como manual para la enseñanza, sino también como libro de lectura o consulta. Durante los siglos XIV y XV el número de bibliotecas universitarias superó a las bibliotecas monásticas y, a partir de 1530 las bibliotecas privadas, tanto reales como aristocráticas, se hicieron mucho más grandes por lo que se generó la necesidad de un material asequible a un público lector que demandaba saber. Aunque la lectura silenciosa en privado era lo habitual a finales de la Edad Media, las lecturas públicas no desaparecieron de las aulas universitarias. Los testimonios iconográficos del momento muestran al profesor leyendo en voz alta a los estudiantes quienes, con frecuencia, tenían entre las manos un libro ya escrito para seguir la lección del profesor. Los estudiantes, a pesar de la creencia general, no se dedicaban a copiar los textos al dictado durante las lecciones, sino que los manuales universitarios se elaboraban antes. Además de la importancia del libro de texto como soporte en el seguimiento de las lecturas públicas, cada vez se va haciendo más común el hábito del estudio individual (Saenger 1998, 205-215).

Es importante, por ello, no solo tener en cuenta la procedencia o profesión del autor de un texto, sino el destinatario o mecenas en caso de conocerlo. Los manuscritos de Torres y el anónimo de la 
Colombina no tienen prólogo ni aparece ninguna indicación sobre el público receptor de la traducción. El impreso de Chaves tampoco indica a quién iba destinado su trabajo. El resto de versiones castellanas de De Sphaera Mundi van dedicadas a un miembro de la nobleza, la realeza o la jerarquía eclesiástica lo que nos lleva a pensar en libros creados para el estudio individual: Maestro de Veas dedica su texto a don Ińigo López de Mendoza, segundo duque del Infantado y marqués de Santillana; Sáenz de Santayana a don Juan de Austria, hijo de Carlos V (I de España) y hermano de Felipe II; Rocamora y Torrano se lo dedica al cardenal Infante D. Fernando de Austria, arzobispo de Toledo; por último, Luis de Miranda a don Luis Fajardo, marqués de los Vélez y de Molina.

Además, los libros en lengua vulgar destinados a la clase aristocrática se caracterizan, precisamente, por contener "índices de materias, glosarios alfabéticos, índices temáticos, títulos y complejidades intelectuales", además de aumentar el número de ilustraciones o figuras (Saenger 1998, 222-223); y es que ésta es también una característica de los manuales: "particularmente en los textos didácticos se utiliza toda clase de recursos -dibujos, recuadros o fondos de diferente color, cambio de tipografía, etcétera- porque ya la puntuación no basta para guiar la interpretación de un lector considerado, a priori, como incompetente" (Emilia Ferreiro 2001, 53 apud Negrín 2009, 193). Así pues, los impresos de Chaves ("Tabla donde se demuestran los lugares por donde passan los climas, según la opinión de los antiguos astrólogos" [CHA 84r]), Rocamora y Torrano ("Tabla del nacimiento y ocaso de los signos en la esfera oblicua septentrional, por los grados y minutos de la equinocial" [GRT 255r]) y Miranda ("Primera tabla, de las ascensiones de los signos en los ocho climas septentrionales, que conocieron los antiguos por grados y minutos" [LDM 200]) incluyen entre sus páginas tablas por considerarlas imprescindibles para la comprensión de los conceptos expuestos; Chaves lo justifica:

Y porque esto sea más notorio y fácil de entender, parecióme que era bien hazer una tabla donde pusiesse algunas insignes ciudades de Espańa con su longitud y latitud que tienen, entendiendo la longitud de aquel meridiano 
señalado por Ptolomeo de que arriba avemos hecho mención, y siguiendo en las latitudines al mismo Ptolomeo y también a la experiencia de lo que oy día se sabe d'ellas en cuanto a esta latitud, donde notarás que la primera cuenta te declara la longitud y la segunda la latitud [CHA 50v].

Si hay un rasgo que caracteriza las explicaciones y comentarios de las versiones castellanas de De Sphaera Mundi (excepto Torres y la anónima de la Colombina), ése es el empleo de dibujos y esquemas para aclarar y ejemplificar la definición de los términos, en especial en los impresos; así, lo gráfico sirve para representar un concepto abstracto como los círculos de los movimientos de los planetas. Incluso se permiten cambiar la figura que ofrecía Sacrobosco en su empeńo por que se comprenda el contenido del manual:

Esta conclusión es expressa de nuestro autor Juan de Sacrobosco, y d'ella se pone la siguiente figura.

Pero aviéndola bien mirado me pareció no seńala de fuera lo que el autor dize en la letra de adentro, y allando otra figura más a propósito, me pareció ponerla aquí, y es la que se sigue [LDM 119-120].

\section{Contenido del Manual}

Los manuales o libros de texto "además de cumplir con su función específica, son documentos históricos, donde se reflejan la ciencia y la pedagogía de cada época, junto a las vivencias experimentadas por cada autor en su particular contexto socio-histórico" (Cornejo 2006), razón por la que nos sirven de guía en la exposición del contenido científico de una época determinada. Sacrobosco hace acopio de ciertas nociones sobre cosmología (teoría aristotélica) y astronomía (teoría ptolemaica) que circulaban en su época, haciendo una compilación al más puro estilo escolástico. Presenta a sus alumnos una idea de la ciencia diferente de la promovida por la filosofía natural basada en explicaciones derivadas de las relaciones causales, al exponer las relaciones matemáticas entre los fenómenos de la naturaleza que se consideran hechos derivados de la experiencia y la observación. 
Su práctica didáctica consistía en explicar a sus alumnos nociones sobre matemáticas, astronomía o cómputo en un estilo narrativo adornado con explicaciones etimológicas, un poco de historia y abundantes citas de los poetas latinos. Estas citas a obras literarias que Sacrobosco acostumbraba a incorporar en sus textos constituyen un rasgo característico de su estilo y era práctica de uso habitual entre los autores del siglo XII con cierta inclinación humanística (apoyarse en autores del pasado era una garantía). En Sacrobosco su uso de las autoridades tiene una clara intención pedagógica, pues facilitaba la comprensión de algunos aspectos difíciles o el acercamiento a un fenómeno desconocido de un modo que resultaba familiar a sus estudiantes después de haber estudiado retórica dentro del Trivium. Los testimonios en castellano del manual de Sacrobosco mantienen esas citas: las versiones de Torres, la anónima de la Colombina, la de Chaves y la de Sáenz de Santayana traducen también estas citas (la última no siempre, como se ve en el ejemplo siguiente); por el contrario las de Maestro de Veas y Miranda las mantienen en latín seguidas de una traducción al castellano o una explicación y la de Rocamora y Torrano sin traducir.

así como dize Ovidio que:

Tantas regiones o plagas se primen de la Tierra, de las cuales la que es media es inhabitable por grand calor. Y la nieve alta cubre las dos. Y asentó la media entre ambas y la flama mesclada con frío les dio templanza [DDT $193 r]$.

como dixo el Ovidio en el Mettamorphoseos, otras tantas plagas son oprimidas en la Tierra:

quarum que media est non est habitabilis estu nixtegit alta duas totidem inter utrasque locauit tempeditemque dedit mixta cum frigore flamma,

que quiere dezir que la zona de medio no se puede morar por el grand calor d'ella, las dos están cubiertas de nieve, y las otras dos están templadas en calor y frío [MDV 14v].

y esto dize Ovidio en el primero libro Metamorfoseos deziendo:

Y otras tantas regiones se imprimen en la Tierra, de las cuales la que es 
media o está en el medio es inabitable que se no puede morar por el grand calor. E la nieve cubre las dos e asentóse la media entre ambas. E la flama templala con frío le dió templança [COL 22v].

de donde Ovidio en el primero de Methamorphoseos dize:

Otras tantas plagas o regiones están sujetas en la Tierra a estas que están en el cielo, de las cuales la que está en medio es inhabitable por el mucho calor. Y la nieve grande cubre las dos extremas que están debaxo de los polos. Y otras dos están puestas entre estas dos frías y la muy caliente, a las cuales dio Dios una templança con la mixtión del calor del medio y con la frialdad de las dos extremas [CHA 53v].

por lo cual Ovidio Metham. 1:

Totidemque plagae tellure premuntur,

Quarum quae media est, non est habitabilis aestu, Nix tegit alta duas, totidem inter vtramque locavit, Temperiemque dedit, mixta cum frigore flamma [sAN 28r-v].

y por esto dixo Ovidio en el primero de los Methamorphosios:

Totidemque plagae tellure premuntur

Quarum quae media est non est habitabilis aestu:

Nix tegit alia duas: to idem interytrique locavit,

Temperiemque dedit, mixta cum frigore flamma [GRT 348v].

de las cuales, hablando Ovidio en el primero libro de sus Metamorfosios, o transmutaciones, dexó también escritos los cuatro siguientes versos:

Totidemque plagae tellure premuntur.

Quarum quae media est, non est habitabilis aestu.

Nix tegit alta duas : totidem inter vtranque locauit.

Temperiemque dedit, mista cum frigore flamma [LDM 157]

La astronomía que se expone en De Sphaera Mundi está basada en la teoría geocéntrica que sitúa la Tierra en el centro del universo, como se había venido defendiendo desde la Antigüedad. En el siglo XVI, el astrónomo de origen polaco Nicolás Copérnico (1473-1543) reintrodujo la teoría heliocéntrica, por la que el Sol se encuentra en 
el centro del universo, en su obra De revolutionibus orbium coelestium libri six (publicada en 1543). Ambas concepciones del universo convivieron en las aulas universitarias como se registra en los estatutos de Covarrubias de la Universidad de Salamanca de 1561: durante el primer año se leerá la Esfera, teóricas de los planetas, tablas y el astrolabio, mientras que durante el segundo curso se leerá el Almagesto de Ptolomeo o el epítome del mismo hecho por Monte Regio o Geber; y, como auténtica novedad, se podía enseñar a Copérnico "si así lo decidía el voto de los oyentes" (Alejo 1998). De modo que se puede entender que la influencia del manual de Sacrobosco basado en el geocentrismo perviviera hasta el siglo XVII a pesar de la introducción del cambio de paradigma un siglo antes.

Las traducciones al castellano no se hacen eco de estos cambios pues se mantienen fieles a la esencia del original. Eso sí, si tenemos en cuenta el proceso de la traducción y lo que esto significaba en la época, podremos entender que cada traductor hiciera el texto de Sacrobosco suyo y lo volcara al castellano pasado por su filtro, por su propia comprensión, interpretación, dominio del tema o finalidad de la nueva edición, dado que los textos estaban expuestos a una apertura de significante y de significado. Con la intención de esclarecer un concepto que el traductor consideraba "oscuro", este tenía total libertad a la hora de modificar el original e introducir añadidos tanto dentro como fuera del texto:

En esa transferencia la misión de los traductores ha sido fundamental, pues su tarea no se ha limitado a verter ideas -y con ellas, palabras- de una lengua a otra, sino que han actuado como copartícipes de la construcción y la difusión del conocimiento, gracias a sus distintos trabajos de adaptación, recopilación, síntesis y divulgación de los textos (Gutiérrez Rodilla 2008).

Dada la libertad que tenían los autores para añadir y/o quitar texto, encontramos en las versiones castellanas, como hemos señalado al referirnos a su estructura y presentación externa, ejemplos adicionales a la explicación de los conceptos del original que sirven para acercar el contenido a la realidad cultural del momento; por ejemplo, se incluyen referencias a lugares conocidos por los receptores del texto: 
La razón de lo cual es porque en aquel sitio nace y se pone, lo cual no acontece a los que habitan en la posición del cielo de nuestra España, Francia y otras provincias [LDM 227].

Y ansí digo que en Barcelona será primero el mediodía que en Çaragoça, y en Çaragoça, primero que en Valladolid, y esto por estar los lugares más propincuos o remotos del oriente [CHA $37 \mathrm{v}$ ].

También a costumbres o dichos cercanos:

Cerca de lo cual dize Juntino que de aquí nació el proverbio que es común entre los españoles de dezir que el día de San Bernabé (que es a once de junio) da el Sol tan derechamente en la Tierra que, entrando por la boca de un cántaro o tinaja, o cualquier otra basija por angosta que sea, da en el suelo y hondón d'ella [LDM 232-233].

O se actualiza el conocimiento:

Cerca de lo cual es de advertir que esto que dize Juntino se ha de entender de lo que se usava en el tiempo que hizo su comento a La Esfera de Sacrobosco, porque después acá á avido grande variación en esto con la reformación que hizo o mandó hazer de los tiempos el Papa Gregorio décimotercero, que fue el año de 1582 a cuatro de octubre. Y ansí agora no entra el Sol en los signos a los dichos doze días de cada mes, sino a los veintiuno, o veintidós, por los diez u once días que el dicho Pontífice quitó al tiempo, pareciéndole que ivan adelantados en espacio de mil años [LDM 175].

En la actualización de los contenidos, puede ocurrir que, para que los lectores desprovistos de conocimientos de la Antigüedad comprendan el texto, el traductor se vea en la necesidad de utilizar el equivalente de su época. Por ejemplo, ante la moneda romana denario, los traductores de De Sphaera Mundi optan por utilizar un equivalente de su época, blanca en [MDV 6v], o por recurrir a un término general, dinero en [DDT 189v] y [COL 10v] y moneda en [CHA 22r] y [SAN 13r].

Esa actualización del contenido puede afectar también al saber de astronomía: en el original de Sacrobosco se explica la existencia 
de nueve esferas celestes (las siete esferas de los siete planetas, la octava esfera de las estrellas fijas o firmamento y la novena esfera responsable del movimiento diurno). Sin embargo, algunos comentaristas y traductores añaden una décima. En los testimonios en castellano se mantiene la estructura en nueve esferas en el cuerpo textual, pero en los comentarios o escolios, los autores hacen referencia a la posible existencia de una décima:

Otros astrólogos añiden otra esfera, y hazen diez. La décima es el primer móbil o movedor, y la nona es el segundo móbil, y luego ponen la octava, y las de los siete planetas [CHA 14r].

Y porque allende d'estos dos movimientos, la octava víamos moverse al movimiento diurno de oriente en occidente cada día, a esta causa estableció por primer móbil sobre todas a la décima, la cual cumple su movimiento proprio (ca ella no tiene otro) en espacio de veinte y cuatro horas [CHA 16v].

Los modernos astrólogos consideran diez esferas o cielos, assí como los pone el Teodorico Jorje Purbachio. La causa es porque en la octava esfera consideran tres movimientos, de los cuales sólo el movimiento que llaman de trepidación dizen ser natural, el cual es considerando el apartamiento que haze del septentrión y allegamiento al mediodía [SAN 10r-v].

Cerca de la dicha conclusión es también de notar que Sacrobosco, poniendo solamente nueve cielos o nueve esferas, habló según la opinión de los astrónomos o astrólogos antiguos, porque de los modernos unos ponen diez, otros once, y otros más [LDM 16].

\section{LÉXICO DE ESPECIALIDAD}

La importancia del lenguaje de especialidad es innegable en la enseñanza pues cuando se aprende una ciencia se hace junto al léxico que recoge los conceptos. La terminología juega, además, un papel crucial en tanto facilita la labor de los traductores al verter los contenidos de una lengua a otra. En su tarea,

El traductor actúa de mediador entre dos interlocutores naturales; [...] debe ponerse en la piel del que emite el mensaje y asumir sus mismas com- 
petencias. [...] Asumir sus competencias, tanto en lo que se refiere a conocimientos como a habilidades, presupone conocer la materia que traduce (porque el emisor conoce el tema del que habla), saber expresarla precisa y adecuadamente y hacerlo como lo haría espontáneamente un especialista, hablante nativo de la lengua (Cabré 2004).

Sin embargo, en el periodo en que se compusieron las primeras versiones de De Sphaera Mundi en castellano la situación era muy diferente pues existía un vacío terminológico que el traductor debía suplir en su labor de trasvase del latín a la lengua romance. En consecuencia, el traductor actuaba como terminólogo para resolver la carencia de términos específicos que no formaban parte del caudal léxico de la lengua en que vertía el original. Por otro lado, la acuñación de unidades de conocimiento especializado en obras de carácter didáctico es un modo de afianzar la terminología y de que se aprenda junto al conocimiento científico.

De lo anterior se desprende que hasta que un término queda establecido dentro de la red conceptual de una materia, puede coexistir junto a otras formas. Era una práctica habitual recoger los conceptos por medio de estructuras binarias yuxtapuestas o coordinadas con la conjunción $o$.

Estas estructuras pueden estar formadas por la acumulación de sinónimos: "espera recta o derecha” [DDT 188v]; "espera derecha o recta" [MDV 4r]; "espera derecha o redondez" [COL 6v]; "esfera recta o derecha, y en esfera obliqua o torcida" [LDM 16]; "no sean del todo círculos, sino espiras o enroscaciones o religaciones" [LDM 210]. Aunque no todas las estructuras sinonímicas son producto de la traducción pues ya estaban en el texto de Sacrobosco por el carácter didáctico del manual: eliacus ortus sive solaris (Thorndike 1949, 97) se traduce "nacimiento elíaco o solar" [DDT 193v]; "nacimiento elíaco o solar" [MDV 16r]; "elíaco [...] o solar nacimiento" [COL 24r]; "orto helíaco o solar" [CHA 57v]; "nacimiento helíaco o solar" [sAN 8r]; "nacimiento elíaco o solar" [GRT 251r]; "nacimiento helíaco o solar” [LDM ].

Aunque también encontramos estructuras que incorporan una glosa explicativa junto al término que sirve de definición: "coluro solsticial" [LDM 139]; "coluro que distingue los solsticios" [DDT 
192r] [CHA 44r] [SAN 37r] [GRT 244v]; "coluro que parte los solsticios" [COL 19r].

Pero los añadidos que mejor reflejan la intención del traductor de transmitir el contenido son aquellos que introducen definiciones de términos de astronomía. En el manual en latín ya aparecían definiciones de términos científicos tan precisas que resultaban fáciles de memorizar y recordar con el paso del tiempo para aquellos alumnos que continuaran sus estudios (Pedersen 1985, 214). Son notas léxicas de carácter lexicográfico insertas en la exposición del traductor. En algunos casos estas notas son definiciones enciclopédicas que completan la explicación del texto original:

el zodiaco es uno de los seis círculos mayores, el cual divide el mundo en dos partes iguales oblicuamente, porque divide el círculo en dos partes, la una metad está a la parte del septentrión, que es desde el principio del signo de Aries por Tauro hasta el fin de Virgo, y la otra metad está a la parte del mediodía, que es desde el principio de Libra por Escorpión hasta el fin de Piscis [san 30v-31r].

Pero en otros momentos encontramos definiciones breves y concisas, como: "Polos se dizen aquellos dos extremos que, en la circunferencia, el diámetro o axe señala con su principio y fin" [SAN 5r]; "gabia (que es lo más alto del mástil)" [LDM 76]; "paralelos (esto es círculos igualmente distantes)" [LDM 210]; "si se mirare por ambos los aguxeros de los mediclinios (que son unos hierrecillos, que están allí levantados)" [LDM 96].

\section{Conclusiones}

Para terminar con el análisis de las claves didácticas de De Sphaera Mundi partimos de las cuatro funciones esenciales que, según Alain Choppin (apud Negrín 200, 191-192), pueden ejercer los libros de texto o manuales:

1. Una función referencial, también llamada curricular o programática: el manual traduce las prescripciones curriculares más amplias y constituye 
el soporte privilegiado de los contenidos educativos, es depositario de conocimientos, de técnicas o de competencias que un grupo social estima necesario transmitir a las nuevas generaciones.

2. Una función instrumental: el manual presenta métodos de aprendizaje, propone ejercicios o actividades que, según los contextos y las épocas, apuntan a facilitar la memorización de conocimientos, a favorecer la adquisición de competencias disciplinares o transversales, la apropiación del savoir faire, de métodos de análisis o de resolución, entre otros propósitos. 3. Una función ideológica y cultural: es ésta la función más antigua. Desde el siglo XIX, con la constitución de los estados-naciones y el desarrollo, en ese proceso, de los principales sistemas educativos, el manual se afirma como uno de los instrumentos esenciales que moldean la lengua, la cultura y los valores de las clases dirigentes.

4. Una función documental: el manual proporciona un conjunto de documentos textuales o icónicos cuya observación o confrontación son susceptibles de desarrollar el espíritu crítico del alumno.

De Sphaera Mundi cumple esa función referencial en tanto conjuga perfectamente las dos corrientes geocéntricas en boga en el momento: la cosmología de Aristóteles y la astronomía matemática de Ptolomeo; en las traducciones se aprecia cómo se van ampliando los conocimientos en el ámbito de la astronomía (por ejemplo, el número de esferas) y el empeño de los autores por transmitir el contenido a través del uso de tablas e imágenes explicativas.

Cumple la función instrumental pues permitía a los estudiantes iniciarse en el complejo mundo de los movimientos celestes y el cálculo de sus posiciones; la división del texto en lecciones, los títulos resaltados tipográficamente o el empleo de notas marginales son aspectos destacables en algunas de las versiones castellanas que las llevan a desempeñar esa función instrumental.

Cumple, además, la función ideológica y cultural, dado que Sacrobosco fue capaz de romper con todas las controversias suscitadas por el pensamiento aristotélico sin entrar en conflicto con los teólogos. De hecho, no hay referencias a Dios como creador del universo o como causa del movimiento de las esferas celestes, por ejemplo; sí aparece una referencia cristiana al final del tratado cuando explica 
los eclipses. Todo en su justa medida: un par de citas tomadas de Aristóteles, de esas que no suscitaban polémica, y una mención a la noche de la Pasión de Jesús, todo ello dentro del marco de la astronomía teórica. El cambio que se estaba produciendo en los hábitos de lectura a mediados del siglo Xvi también queda reflejado en el hecho que se elaborasen traducciones para representantes de la nobleza, el clero o la realeza.

Por último, cumple también la función documental por la cantidad de versiones con comentarios que fueron surgiendo en latín y en otras lenguas como testimonio del espíritu crítico que despertó en aquellos que estudiaron sus contenidos.

El manual de Sacrobosco, con esa apertura de significante y significado habitual en los textos medievales, va evolucionando en sus reediciones en latín y, como hemos visto, en las traducciones a otras lenguas adaptándose a los cambios sociales (auge de las bibliotecas privadas y hábitos de lectura) y científicos (se acuñan nuevos términos para nuevos conceptos) de cada época pero manteniendo la esencia del libro de texto.

Quizá el éxito de De Sphaera Mundi radique en el cambio social que se estaba produciendo a finales de la Edad Media en tanto la astronomía se vio en la necesidad de atender las necesidades prácticas de esa nueva sociedad que estaba preocupada por las reformas del calendario, que estaba descubriendo nuevos horizontes y necesitaba textos sobre cartografía y astronomía náutica, y que sentía la astrología como parte de su vida y su destino.

\section{REFERENCIAS BIBLIOGRÁFICAS}

Alejo Montes, Javier, La Universidad de Salamanca bajo Felipe II 1575-1598, Burgos, Junta de Castilla y León (Consejería de Educación y Cultura), 1998.

CABRÉ, Ma . Teresa, "La terminología en la traducción especializada”, en Consuelo Gonzalo García y Valentín García Yebra, eds., Manual de documentación y terminología para la traducción especializada, Madrid, Arco/Libros, 2004, 89-122, disponible en línea $[20 / 12 / 2011]$. 
Cornejo, Jorge Norberto, "El análisis de manuales escolares y la historia de la enseñanza de la ciencia como recurso en la formación docente", Revista Iberoamericana de Educación, 38 (6), 2006, en línea [20/12/2011].

Gómez Martínez, Marta, Sacrobosco en castellano, Salamanca, Ediciones Universidad de Salamanca, 2006.

Gutiérrez Rodilla, Bertha M., "La impronta de la traducción sobre el discurso científico: toda una historia", Puntoycoma, 106, 2008, 17-30, en línea [20/12/2011].

Grant, Edward, Physical Science in the Middle Ages, Cambridge, Cambridge University Press, 1986 [1 $1^{\text {a }}$ ed. 1977].

Grant, Edward, The Foundations of Modern Science in the Middle Ages. Their Religious, Institutional and Intellectual Contexts, Nueva York, Cambridge University Press, 1996.

LefF, Gordon, "El Trivium y las tres filosofías", en Hilde de RidderSymoens, ed., Historia de la universidad en Europa, vol. I, Bilbao, Universidad del País Vasco, 1994, 351-384.

López Piñero, José Ma., Thomas F. Glick, Víctor Navarro y Eugenio Portela, Diccionario histórico de la ciencia moderna en España, Barcelona, Península, 1983.

Negrín, Marta, "Los manuales escolares como objeto de investigación”, Educación, lenguaje y sociedad, vi, núm. 6, 2009, 187-208. Pedersen, Olaf, "In Quest of Sacrobosco", Journal for the History of Astronomy, XVI, 1985, 175-221.

SAEnger, Paul, "La lectura en los últimos siglos de la Edad Media", en Guglielmo Cavallo y Roger Chartier, dirs., Historia de la lectura en el mundo occidental, Madrid, Taurus, 1998, 189-230.

Thorndike, Lynn, The 'Sphere' of Sacrobosco and Its Commentators, Chicago, The University of Chicago Press, 1949.

FECHA DE RECEPCIÓN DEL ARTíCULO: 12 de enero de 2012 FECHA DE RECEPCIÓN DE LA VERSIÓN FINAL: 14 de enero de 2013 